\title{
Study on Nonequilibrium Effect of Condensate Gas Reservoir with Gaseous Water under HT and HP Condition
}

\author{
Dali Hou, Pingya Luo, Lei Sun, Yong Tang, and Yi Pan \\ The State Key Laboratory of Oil \& Gas Reservoir Geology and Exploitation Engineering, Southwest Petroleum University, \\ Xindu Avenue No. 8, Chengdu, Sichuan Province 610500, China \\ Correspondence should be addressed to Dali Hou; houdali08@163.com
}

Received 23 November 2013; Revised 17 January 2014; Accepted 10 February 2014; Published 9 April 2014

Academic Editor: Davide Vione

Copyright (C) 2014 Dali Hou et al. This is an open access article distributed under the Creative Commons Attribution License, which permits unrestricted use, distribution, and reproduction in any medium, provided the original work is properly cited.

\begin{abstract}
When a condensate gas reservoir with gaseous water under high temperature and high pressure condition is producing, the gaseous water and nonequilibrium effect will have great influences on the phase behavior of condensate oil and gas system and the accumulation of condensate liquid near the wellbore area. Therefore, a series of experiments were performed to investigate phase behavior of the condensate gas reservoirs with gaseous water using a PVT cell, in which the constant volume depletion process of nonequilibrium pressure drop and equilibrium pressure drop within near wellbore zone was simulated. And using the modified PR EOS, PR EOS, and nonequilibrium effect theory, the authors calculated the content of condensate oil and condensate liquid of the nonequilibrium pressure drop and equilibrium pressure drop and compared the calculated results with the experimental data. The results show that the modified PR EOS combined with nonequilibrium effect theory is more suitable for representing phase behavior characteristics of the development process of condensate gas reservoir containing gaseous water, with the average relative error of $4.49 \%$. Furthermore, choosing the appropriate exploiting opportunity and properly increasing the nonequilibrium effect are helpful to increase condensate oil and water recovery.
\end{abstract}

\section{Introduction}

Condensate reservoir with gaseous water is an important part of oil-gas resources [1-3]. Studies have shown that the influence of formation water on condensate gas phase behavior cannot be ignored. The reason is that water in the gas phase mixes with gaseous hydrocarbon under high temperature and high pressure condition, and the polarity of the water molecule leads to a change in the phase behavior of condensate gas in the systems that contain gaseous water [4-9]. Because the water molecule is polar, the conventional hydrocarbon system equation of state is no longer adapted to describe the condensate gas reservoirs with gaseous water. Nichita et al. predicted the phase equilibrium data by using the modified Peng-Robinson EOS, which utilized the different binary interaction parameters in the aqueous and hydrocarbon gases [5]. Oliveira et al. utilized the CPA EOS to accurately describe the mutual solubilities of water and several aliphatic and aromatic hydrocarbons in a broad range of pressures and temperatures [6]. Pedersen and Milter measured phase equilibrium data for the mutual solubility of brine and a gas condensate mixture at temperatures ranging from $35^{\circ} \mathrm{C}$ to $200^{\circ} \mathrm{C}$ and pressures of $70 \mathrm{MPa}$ to $100 \mathrm{MPa}$ [7]. These experimental data were modeled using the PR EOS with the nonclassical mixing rule of Huron and Vidal. The simulation results are in good agreement with the experimental data even at high pressure and high temperature. Lindeloff and Michelsen calculated the pressure-temperature phase diagrams for hydrocarbon-water mixtures using the SRK EOS with temperature dependent Peneloux volume shift [8].

During the development process of condensate gas reservoirs with gaseous water, both reservoir pressure and wellbore pressure decrease gradually. Retrograde condensation takes place as soon as reservoir pressure falls below the dew point of gas condensate with gaseous water in place, which includes the change of single-phase flow into oil-gas-water three-phase flow [10]. There is no time to reach fully phase equilibrium between gas and liquid phase because of a highspeed flow of the gas phase. A part of the precipitation liquid 
phase moves slowly and gradually settles due to the porous media adsorption effect of the rock surface, which is caused by the remaining free energy of the rock surface. The other part of the precipitation liquid phase entrained in the gas phase moves a distance with high speed and then forms the liquid. This is the so-called "precipitate lag" phenomenon, namely, the nonequilibrium effect [11]. Therefore, the phase behavior analysis method of condensate gas based on the equilibrium theory cannot simulate the real nonequilibrium process of oil and gas system near the wellbore zone [1216]. Moreover, a conventional phase behavior experiment based on the equilibrium theory needs to consume large amounts of time and the experimental analysis process is not consistent with the actual gas field exploitation [17-19]. Currently, there are few relevant experimental reports on the phase behavior of gas condensate with gaseous water in the process of nonequilibrium pressure drop. Therefore, it is necessary to carry out experimental research on this topic and the experimental results have a very important engineering significance for the actual production of a gas condensate with gaseous water.

In this work, simulation modeling and experimental analysis of nonequilibrium effect in the gas condensate with gaseous water are considered. The main purpose is to compare the phase behavior data considering gaseous water in the process of the nonequilibrium pressure drop with the phase behavior data considering gaseous water in the process of the equilibrium pressure drop.

\section{Theory}

2.1. Thermodynamic Model for a Gas-Condensate/Water System. The Peng-Robinson equation of state [20] is one of the most widely used for engineering EOS:

$$
P=\frac{R T}{V-b}-\frac{a(T)}{V(V+b)+b(V-b)} .
$$

For a pure fluid, constant $b$ is given by

$$
b_{i}=0.007780\left(\frac{R T_{c i}}{P_{c}}\right) .
$$

While $a(T)$, a function of temperature, is given by

$$
\begin{gathered}
a_{i}(T)=a_{i}\left(T_{c i}\right) \times \alpha_{i}\left(T_{r i}, \omega_{i}\right), \\
a_{i}\left(T_{c i}\right)=0.45724 \frac{R^{2} T_{c i}^{2}}{P_{c i}}, \\
\alpha_{i}\left(T_{r i}, \omega_{i}\right)=\sqrt{1+m\left(1-T_{r i}^{1 / 2}\right)}, \\
m=0.37464+1.54226 \omega_{i}-0.26992 \omega_{i}^{2} .
\end{gathered}
$$

A simple classical Van der Waals mixing rule with one binary interaction parameter $k_{i j}$ is used to calculate mixture systems:

$$
\begin{gathered}
a_{m}(T)=\sum_{i=1}^{n} \sum_{j=1}^{n} x_{i} x_{j}\left(a_{i} a_{j} \alpha_{i} \alpha_{j}\right)^{0.5}\left(1-k_{i j}\right), \\
b_{m}=\sum_{i=1}^{n} x_{i} b_{i} .
\end{gathered}
$$

For polar-non-polar interactions, however, the classical Van der Waals mixing rule for the attractive parameter $a$ is not satisfactory and an unconventional form of the classical mixing is required. In this study, Huron and Vidal's modified attractive parameter $a$ is introduced, which combines Van der Waals mixing rule with activity coefficient [7]. The Huron and Vidal's modified attractive parameter $a$ is expressed:

$$
a=b\left(\sum_{i=1}^{n}\left(x_{i} \frac{a_{i}}{b_{i}}\right)-\frac{G_{\infty}^{E}}{\lambda}\right) .
$$

$\lambda$ is a constant, which has different values for different EOS. For PR EOS, it is equal to the following value:

$$
\lambda=\frac{1}{2 \sqrt{2}} \ln \left(\frac{\sqrt{2}+1}{\sqrt{2-1}}\right) .
$$

$G_{\infty}^{E}$ represents Gibbs free energy at infinite pressure, which is computed using modified NRTL mixing rule:

$$
\frac{G_{\infty}^{E}}{R T}=\sum_{i=1}^{n} x_{i} \frac{\sum_{j=1}^{n} \tau_{j i} b_{j} x_{j} \exp \left(-\alpha_{j i} \tau_{j i}\right)}{\sum_{k=1}^{n} b_{k} x_{k} \exp \left(-\alpha_{k i} \tau_{k i}\right)} .
$$

$\alpha_{i j}$ is not a random parameter; $\tau_{i j}$ represents the intermolecular forces:

$$
\tau_{i j}=\frac{g_{j i}-g_{i i}}{R T},
$$

where $g_{j i}$ is the energy characteristic parameters between the component $j$ and component $i$, which is expressed as a function of temperature. The expression is as follows [7]:

$$
g_{j i}-g_{i i}=\left(g_{j i}-g_{i i}\right)^{\prime}+T\left(g_{j i}-g_{i i}\right)^{\prime \prime} .
$$

Here, $\left(g_{j i}-g_{i i}\right)^{\prime}$ and $\left(g_{j i}-g_{i i}\right)^{\prime \prime}$ have nothing to do with temperature.

When $\alpha_{i j}=0$, there is

$$
\begin{gathered}
g_{i i}=-\frac{a_{i}}{b_{i}} \lambda, \\
g_{j i}=-2 \frac{\sqrt{b_{i} b_{j}}}{b_{i}+b_{j}}\left(g_{i i} g_{j j}\right)^{0.5}\left(1-k_{i j}\right) .
\end{gathered}
$$

The Huron-Vidal mixing rules are simplified as classical Van der Waals mixed rules. This model can be used to calculate phase equilibrium parameters for the systems containing polar material, such as the system containing the condensate gas, condensate oil, and gaseous water. 
TABLE 1: Composition of the reservoir fluid studied.

\begin{tabular}{lcc}
\hline Components & ${ }^{1} \mathrm{~mol} \%$ & ${ }^{2} \mathrm{~mol} \%$ \\
\hline $\mathrm{H}_{2} \mathrm{O}$ & 1.52 & 0.00 \\
$\mathrm{CO}_{2}$ & 2.40 & 2.43 \\
$\mathrm{~N}_{2}$ & 6.05 & 6.14 \\
$\mathrm{C}_{1}$ & 80.54 & 81.76 \\
$\mathrm{C}_{2}$ & 4.36 & 4.43 \\
$\mathrm{C}_{3}$ & 1.59 & 1.61 \\
$i \mathrm{C}_{4}$ & 0.25 & 0.25 \\
$n \mathrm{C}_{4}$ & 0.51 & 0.52 \\
$i \mathrm{C}_{5}$ & 0.17 & 0.17 \\
$n \mathrm{C}_{5}$ & 0.21 & 0.21 \\
$\mathrm{C}_{6}$ & 0.03 & 0.03 \\
$\mathrm{C}_{7}$ & 0.08 & 0.08 \\
$\mathrm{C}_{8}$ & 0.16 & 0.16 \\
$\mathrm{C}_{9}$ & 0.27 & 0.27 \\
$\mathrm{C}_{10}$ & 0.32 & 0.33 \\
$\mathrm{C}_{11+}$ & 1.57 & 1.49 \\
\hline Total & 100 & 100 \\
\hline
\end{tabular}

${ }^{1}$ The components of the synthetic condensate gas sample with gaseous water; properties of the $\mathrm{C}_{11+}$ : molecular weight, $217.9(\mathrm{~g} / \mathrm{mol})$; density at 293.15 , $0.8560 \mathrm{~g} / \mathrm{cm}^{3}$.

${ }^{2}$ The components of the synthetic condensate gas sample without gaseous water; properties of the $\mathrm{C}_{11+}$ : molecular weight, $211.7(\mathrm{~g} / \mathrm{mol})$; density at $293.15,0.8499 \mathrm{~g} / \mathrm{cm}^{3}$.

\subsection{Nonequilibrium Pressure Drop Theory. A.X.} МИРЗАДЖАНЗАДЕ has done a lot of research on the nonequilibrium effect for condensate gas system and proposed a correlation about the relationship between the condensate oil content and pressure change speed in the process of nonequilibrium pressure drop [19]. The correlation is as follows:

$$
q=A\left(p_{b}-p+\int_{0}^{t} K(T-\tau) \frac{d p(\tau)}{d \tau} d \tau\right)
$$

where

$$
\begin{gathered}
A=\frac{q_{\max }}{\left(p_{b}-p_{\max }\right)}, \\
K(t)=K_{0} e^{-t / T} .
\end{gathered}
$$

Here, $p_{b}, p_{\max }$, and $p$, respectively, represent the dew point pressure, the maximum retrograde condensation pressure, and the system pressure; $q$ and $q_{\max }$, respectively, represent the yield of retrograde condensate oil at present pressure and the yield of retrograde condensate oil at maximum retrograde condensation pressure, $\mathrm{cm}^{3} / \mathrm{min} ; K_{0}$ is the weight coefficient, here, $K_{0}=0.21 ; T$ represents the relaxation time, here, $T=$ $8800 \mathrm{~s} ; t$ represents the time in $\mathrm{s}$.

When the pressure change rate is infinitesimal; that is, $t=$ $T$

$$
q=A\left(p_{b}-p\right)
$$

According to the equation of condensate oil content in the nonequilibrium pressure drop, the expression of mole fraction for condensate oil in the instantaneous nonequilibrium phase change can be deduced:

$$
L^{\prime}=L\left(1+\frac{\int_{0}^{t} K(T-\tau)(d p(\tau) / d \tau) d \tau}{\left(p_{b}-p\right)}\right),
$$

where $L^{\prime}$ represents the mole fraction of condensate oil in the instantaneous nonequilibrium phase change; $L$ represents the mole fraction of condensate oil in the equilibrium phase change, which is calculated by the modified PR EOS.

\section{Experiment}

3.1. Sample Preparation. The experimental oil and gas samples were directly taken from surface separator in YKL6 well in the gas condensate field of Northwest Oilfield Company, Xijiang, China. The condensate oil content of the YKL6 well is $206 \mathrm{~g} / \mathrm{m}^{3}$. The original formation pressure is $58.72 \mathrm{MPa}$, the formation temperature is $136.5^{\circ} \mathrm{C}$, the stable gas-oil ratio is $4165.7 \mathrm{~m}^{3} / \mathrm{m}^{3}$, the density of stock tank oil is $0.7405 \mathrm{~g} / \mathrm{cm}^{3}$, and saturation pressure is $56.85 \mathrm{MPa}$. Furthermore, it is a condensate gas reservoir with gaseous water.

Strictly speaking, this is a synthetic condensate gas sample using the separator gas sample and the separator oil sample in the lab. For more detailed descriptions about synthesis process see SY/T5542-2009 [21]. The measured gas-oil ratio and oil density of synthetic condensate gas sample by twophase flash experiment are $4207.5 \mathrm{~m}^{3} / \mathrm{m}^{3}$ and $0.7482 \mathrm{~g} / \mathrm{cm}^{3}$, respectively. It is very close to the abovementioned stable gas-oil ratio and stock tank oil density. It is a suggestion that the synthetic condensate gas sample is reasonably representative; thus the test results can be used to guide the oil field production practice. The flash gas sample and oil sample were analyzed using a HP-6890 gas Chromatograph and an Agilent-7890A oil chromatograph. The precision of components analyses is around \pm 0.01 ( $\mathrm{mol} \%)$. The measured gas-oil ratio data and the components of flashed gas and oil were then used to calculate the components of reservoir fluid (Table 1). The ion concentrations of formation water were analyzed by high-performance ion-exchange chromatography (HPIC) with two ion-exchange columns (NJ-3A-4A, $250 \mathrm{~mm}, 4.6 \mathrm{~mm}$; Grace609121268, $100 \mathrm{~mm}, 4.6 \mathrm{~mm}$ ) and a suppressed conductivity detection. The minimum detection limit of the HPIC was $0.05 \mathrm{mg} \cdot \mathrm{kg}^{-1}$. The ion concentrations analysis result of formation water is shown in Table 2 . According to the original water saturation, a certain proportion of formation water was added to the condensate gas sample in the PVT cell to obtain synthetic condensate gas sample with gaseous water. The added formation water and the condensate gas sample were stirred well for 2 hours and reached saturated state. Thereafter a two-phase flash experiment was carried out for the synthetic condensate gas sample with gaseous water under the constant original formation pressure condition. The measured gas-oil ratio of synthetic condensate gas sample with gaseous water by two-phase flash experiment is $4008.5 \mathrm{~m}^{3} / \mathrm{m}^{3}$. The flash gas 
TABLE 2: Properties of formation water.

\begin{tabular}{|c|c|c|c|c|c|c|c|c|}
\hline \multirow{3}{*}{ Gas well no. } & \multicolumn{2}{|c|}{ Formation water } & \multicolumn{6}{|c|}{ Amount of ions of formation water $(\mathrm{mg} / \mathrm{L})$} \\
\hline & $\rho^{1}$ & $\mathrm{TDS}^{2}$ & & & & & & \\
\hline & $\mathrm{g} / \mathrm{cm}^{-3}$ & $\mathrm{mg} / \mathrm{L}$ & $\mathrm{HCO}_{3}^{-}$ & $\mathrm{Cl}^{-}$ & $\mathrm{SO}_{4}{ }^{2+}$ & $\mathrm{Ca}^{2+}$ & $\mathrm{Mg}^{2+}$ & $\mathrm{Na}^{+}+\mathrm{K}^{+}$ \\
\hline YKL6 & 1.121 & 176336.3 & 276.45 & 107919.37 & 100 & 8400.25 & 967.02 & 58673.21 \\
\hline
\end{tabular}

sample and oil sample of the synthetic condensate gas sample with gaseous water were also analyzed using a HP-6890 gas Chromatograph and an Agilent-7890A oil chromatograph. The condensate water mass was measured by electronic balance and then the water vapor content was calculated [22]. According to the water vapor content, the mole fraction of gaseous water was calculated as follows [23].

In the hypothesis the gas is $1 \mathrm{~m}^{3}$, the moles of the gas at $20^{\circ} \mathrm{C}, 0.1 \mathrm{MPa}$ are

$$
n_{g}=\frac{1}{V_{m}} .
$$

Here, the $V_{m}$ is equal to 24.5 .

The gaseous water mole fraction is

$$
y_{w}=\frac{W}{M_{w} n_{g}} .
$$

The modified component of the synthetic condensate gas sample with gaseous water is expressed as follows:

$$
y_{i(\text { modified })}=\left(1-y_{w}\right) y_{i} .
$$

$y_{i}$ is the component of reservoir fluid.

Thus, the different components of the synthetic condensate gas sample with gaseous water were obtained. The results are shown in Table 1.

As is shown in Table 1, the mole fraction of gaseous water component in the condensate gas with gaseous water is $1.52 \%$. Therefore the mole fraction of volatile components and gas-oil ratio in the condensate gas with gaseous water are slightly lower than the mole fraction of volatile components and gas-oil ratio in the condensate gas without gaseous water. In contrast, the mole fraction and molecular mass of $\mathrm{C}_{11+}$ components are higher in the condensate gas with gaseous water, which suggests that the presence of gaseous water increases the content of $\mathrm{C}_{11+}$ components in the condensate gas system and increases the weight of the system.

3.2. Apparatus. The experimental facility is a mercury-free high pressure PVT system made by the DBR Company, Canada. A schematic diagram of the corresponding apparatus is given in Figure 1. It is mainly characterized by the visual observation of experimental phenomena and the specially designed piston in the PVT cell that allows to precisely measure even minute liquid. The system is mainly made up of PVT cell, thermostatic air bath, pressure sensor, temperature sensor, sample container, automatic pump, and operation control system. Sample container is made from sapphire glass.

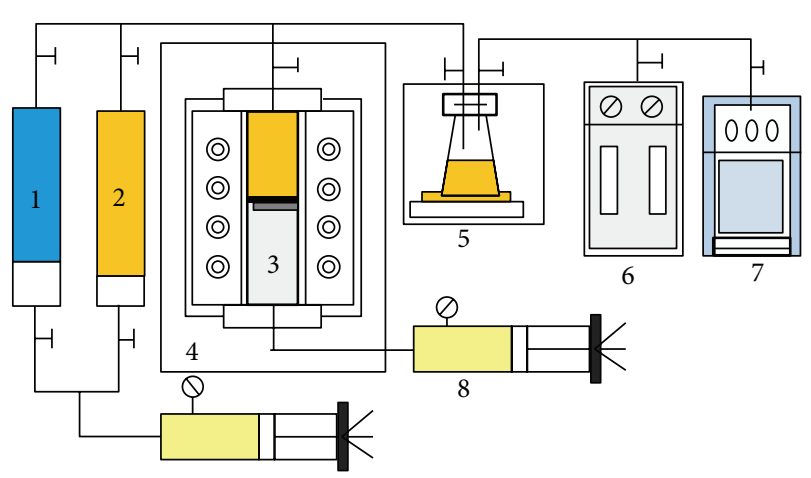

Figure 1: Schematic diagram of the experimental apparatus. 1-water sample, 2-condensate gas sample, 3-PVT cell, 4thermostatic system, 5-oil and gas water separation devices and electronic balance, 6-gasometer, 7-oil and gas chromatography, 8 -automatic pump.

The volume of fluid in the PVT cell can be calculated by the internal cross-sectional area of sapphire glass cylinder multiplied by the height of the fluid, which was measured by the grating altimeter.

The physical parameters of main parts are as follows.

PVT cells: maximal working pressure is $70 \mathrm{MPa}$, the highest operating temperature is $200^{\circ} \mathrm{C}$, and maximal volume is about $150 \mathrm{~cm}^{3}$.

Pressure sensor: $0 \sim 100 \mathrm{MPa}$, precision of pressure control is 1 Psi.

Temperature sensor: $0 \sim 200^{\circ} \mathrm{C}$, precision of temperature control is $\pm 0.1^{\circ} \mathrm{C}$.

Thermostatic air bath: highest operation temperature is $200^{\circ} \mathrm{C}$ and precision of temperature control is $\pm 0.1^{\circ} \mathrm{C}$.

Sample container: $130 \mathrm{~cm}^{3}$.

Automatic pump: rated operation pressure is $100 \mathrm{MPa}$ with resolution of 1 Psi, the range of operation pump volume is $500 \mathrm{~cm}^{3}$ with resolution of $0.001 \mathrm{~cm}^{3}$.

The accuracy of PVT main parts satisfies the phase behavior experimental requirement of the synthetic condensate gas sample containing gaseous water.

\subsection{Experimental Procedure}

(1) Clean PVT cells and then connect the vacuum pump to the PVT cells and evacuate the cells. 
(2) Control and maintain the formation temperature using the thermostatic air bath.

(3) Introduce a certain proportion of the synthetic condensate gas sample and excess formation water into PVT cells to a formation pressure, adjust the oven through thermostat to the formation temperature; stir the condensate gas sample and formation water for 1 hour and discharge superfluous water sample, and then maintain for $30 \mathrm{~min}$ and measure the condensate gas sample volume of the PVT cells.

(4) Depressurize to the dew point pressure, balance for 1 hour, and record the volume of the sample in the PVT cells. The volume is expressed as $V_{c}$ (it is used to calculate the condensate oil saturation and the condensate oil and gas recovery).

(5) It is evenly divided into $6 \sim 8$ pressure drop between the dew point pressure and the proposed abandonment pressure. Depressurize to the each desirable pressure and balance the system for half an hour or more and then record the total volume of the sample and the volume of the condensate oil in the PVT cell.

(6) Slightly open the valve between the cells and discharge gas from the PVT cells into the flash separators. When the volume of the sample in the PVT cells is equal to the $V_{c}$, the process of discharge gas is over. At the same time, the volume of gas and the mass of the oil and water are, respectively, measured and the components of oil and gas are analyzed using the oil and gas chromatography.

(7) Repeat steps (4) (5), until the last level of pressure.

(8) Slightly open the valve between the cells and depressurize to the atmospheric pressure, discharge gas from the PVT cells into the flash separators, and record the volume of the condensate oil and gas and the volume of condensate water; the flash gas sample and oil sample are analyzed using a HP6890 gas Chromatograph and an Agilent-7890A oil chromatograph.

The above experiment steps were the equilibrium pressure drop constant volume depletion experiment. In the nonequilibrium pressure drop constant volume depletion experiment, continuously depressurize in a certain rate $(d p / d t=0.007 \mathrm{MPa}, d p / d t=0.028 \mathrm{MPa})$ in step (5) and then discharge gas from the PVT cells selecting the corresponding pressure in the equilibrium pressure drop constant volume depletion experiment (bleed gas before the pressure get balanced). Record the total volume of the sample in the PVT cells, the volume of condensate oil in the PVT cells, the volume of the condensate oil and gas, and the volume of condensate water in the flash separators. The flash gas sample and oil sample are analyzed using a HP-6890 gas Chromatograph and an Agilent-7890A oil chromatograph.

\section{Results and Discussion}

4.1. Analysis for the Condensate Oil Recovery. The condensate oil accumulation recoveries in the equilibrium pressure

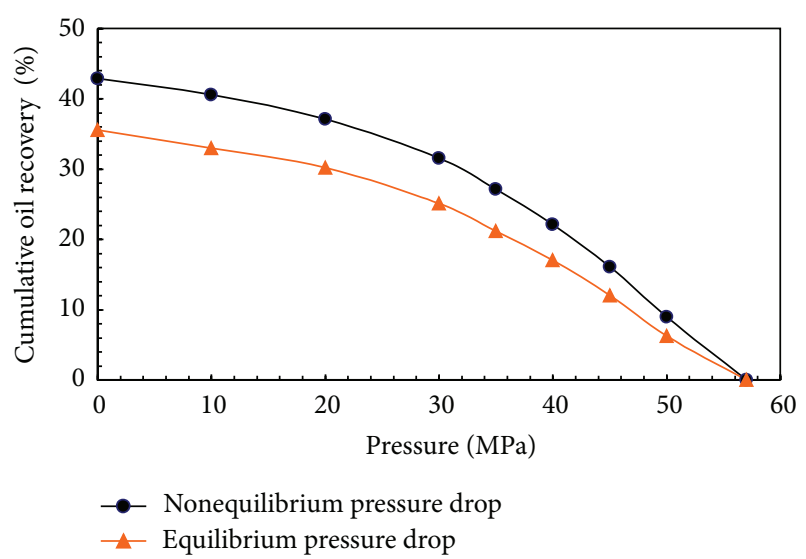

FIgURE 2: The condensate oil accumulation recovery in the equilibrium pressure drop and nonequilibrium pressure drop constant volume depletion experiment.

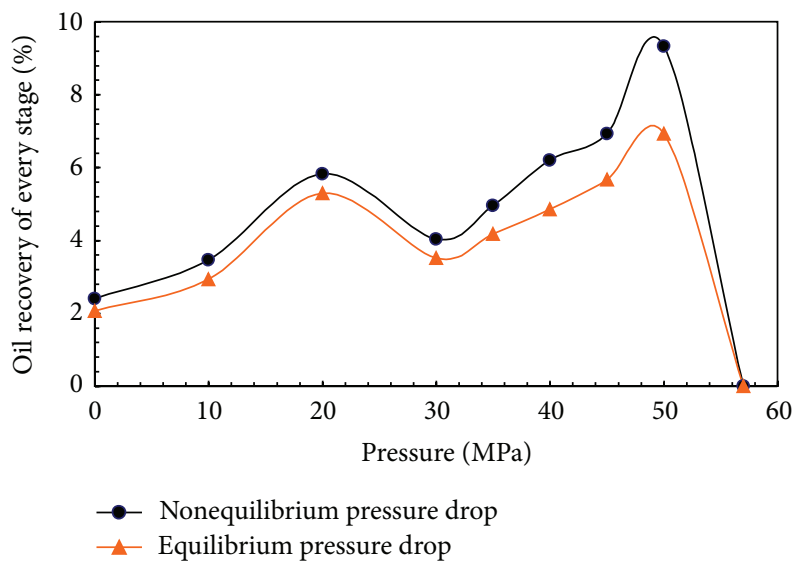

FIgURE 3: The condensate oil recovery under each pressure point in the equilibrium pressure drop and nonequilibrium pressure drop constant volume depletion experiment.

drop and nonequilibrium pressure drop constant volume depletion experiment are shown in Figure 2. As is shown in Figure 2, the condensate oil recovery under each pressure point in the nonequilibrium pressure drop constant volume depletion experiment is higher than in the equilibrium experiment. The ultimate recovery is $42.55 \%$ in the nonequilibrium experiment, which is $6.4 \%$ more than the ultimate recovery in the equilibrium experiment. The reason is that the system stability time does not reach the oil and gas separation equilibrium time in the nonequilibrium experiment, which makes the condensate liquid in the form of mist existing in the gas phase and then produces to the ground with natural gas. Therefore, an appropriate nonequilibrium effect in the production process can improve condensate oil recovery.

The condensate oil recovery under each pressure point in the equilibrium and nonequilibrium experiment is shown in Figure 3. As shown in Figure 3, the condensate oil recovery under each pressure in the nonequilibrium experiment is higher than the condensate oil recovery under each pressure in the equilibrium experiment. Moreover, the condensate oil 


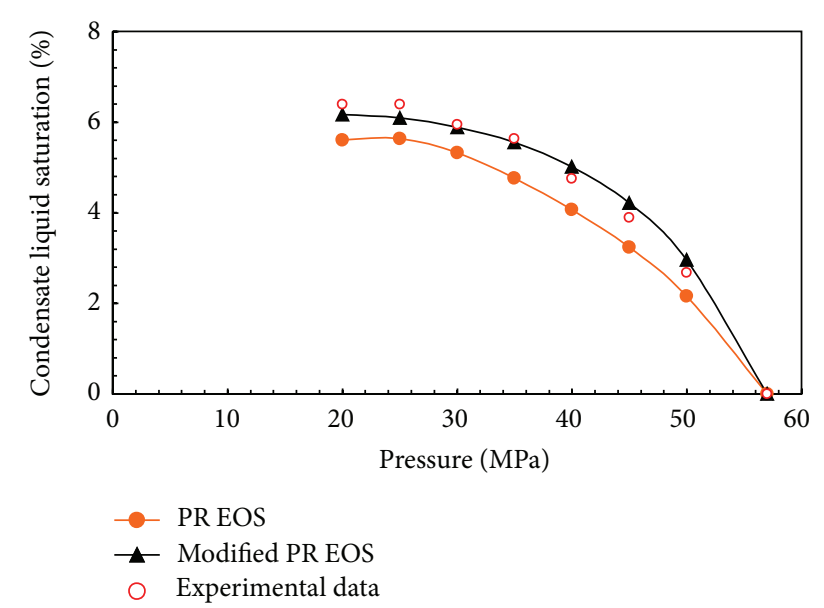

FIGURE 4: The contrast curve about the calculated retrograde condensate oil saturation in the equilibrium pressure drop by the modified PR EOS and PR EOS, the measured retrograde condensate oil saturation in the equilibrium pressure drop constant volume depletion experiment.

recovery increases rapidly when the pressure is higher than the maximum retrograde condensation pressure $(35 \mathrm{MPa})$. But the growth rate of the condensate oil recovery in the nonequilibrium experiment is close to the growth rate of the condensate oil recovery in the equilibrium experiment when the pressure is lower than the maximum retrograde condensation pressure $(35 \mathrm{MPa})$. The main reason for this difference is that the condensate oil content is very high when the pressure is higher than the maximum retrograde condensation pressure. During the pressure reduction period the system mainly undergoes a retrograde condensation process which generates more oil condensate during the gas production process in the nonequilibrium experiment. The system mainly undergoes reverse evaporation and the condensate oil content is very low in the condensate gas when the pressure is lower than the maximum retrograde condensation pressure. At this time the produced condensate oil during the gas production process mainly extracts and evaporates the retrograde condensation oil. Therefore, the condensate oil recovery under each pressure point in the nonequilibrium experiment is close to the condensate oil recovery under each pressure in the equilibrium experiment in the later period of constant volume depletion experiment. It is also a suggestion that in the middle and later periods of condensate gas field development, the nonequilibrium effect is weak.

4.2. Analysis for the Condensate Water. In the constant volume depletion experiment, when pressure reduces to $10 \mathrm{MPa}$, the content of produced condensate water in equilibrium and nonequilibrium pressure drop is, respectively, $20.72 \mathrm{~kg} / 10^{3} \mathrm{~m}^{3}$ and $36.67 \mathrm{~kg} / 10^{3} \mathrm{~m}^{3}$. And when the pressure reduces to the atmospheric pressure, the content of produced condensate water in equilibrium and nonequilibrium pressure drop is, respectively, $250.95 \mathrm{~kg} / 10^{3} \mathrm{~m}^{3}$ and $311.90 \mathrm{~kg} / 10^{3} \mathrm{~m}^{3}$. Those data show that the content of produced condensate water in nonequilibrium pressure drop is higher than that in equilibrium pressure drop under the different pressure. The amount of produced condensate water is mainly related to the stabilization time. In the nonequilibrium experiment, the stabilization time does not reach balanced time, so liquid water exists in gas phase in the form of small droplets and is produced together with the gas. That is why the content of produced condensate water in nonequilibrium pressure drop is higher than that in equilibrium pressure drop. Moreover, the experimental result shows that the content of produced condensate water in the low pressure stage is far higher than that of high pressure stage. This happens because the differential pressure near the wellbore zone is large during the production process of condensate gas reservoirs and the well bottom hole pressure is low, which causes the gas effective permeability to drop sharply and the gas well production capacity to correspondingly decrease. This is the famous "reverse dialysis water lock phenomenon." So it is vitally important to prevent the condensate water from undergoing the reversing osmosis water lock near the wellbore area in the low pressure stage.

4.3. Modified PR EOS Adaptability Analysis. The average relative error is defined:

$$
\varepsilon=\frac{1}{n} \sum_{i=1}^{n}\left|\frac{S_{o c a l}}{S_{o \text { exp }}}-1\right| \times 100 \%,
$$

where $\varepsilon$ is the average relative error; $S_{\text {ocal }}$ is the calculated retrograde condensate oil saturation, decimal; $S_{o \exp }$ is the measured retrograde condensate oil saturation, decimal; $n$ is the number of experimental points.

The condensate oil saturation calculated by conventional PR equation, modified PR equation considering the gaseous water and the measured condensate oil saturation in the equilibrium experiment are shown in Figure 4. As is shown in Figure 4, the condensate oil saturations calculated by modified PR EOS considering the gaseous water are close to the measured condensate oil saturation. According to (18), the average relative errors of conventional PR equation and modified PR EOS are, respectively, $12.83 \%$ and $4.49 \%$. It is a suggestion that the modified PR equation is more suitable for representing the phase behavior characteristics of condensate gas system with gaseous water under the high temperature and high pressure condition.

According to the calculated retrograde condensate oil saturation in the process of equilibrium pressure drop by modified PR EOS, we calculated the retrograde condensate oil saturation at different pressure drop rates $(d p / d t=$ $0.007 \mathrm{MPa}, d p / d t=0.028 \mathrm{MPa})$ in the nonequilibrium pressure drop using (15). The curve of the pressure versus the calculated retrograde condensate oil saturation is shown in Figure 5.

As is shown in Figure 5, the more serious is the nonequilibrium effect and the greater is the pressure drop rate, the greater the retrograde condensate oil saturation of the nonequilibrium pressure drop deviates from the retrograde condensate oil saturation of the equilibrium pressure drop. Moreover, the greater the degree of pressure drop, the 


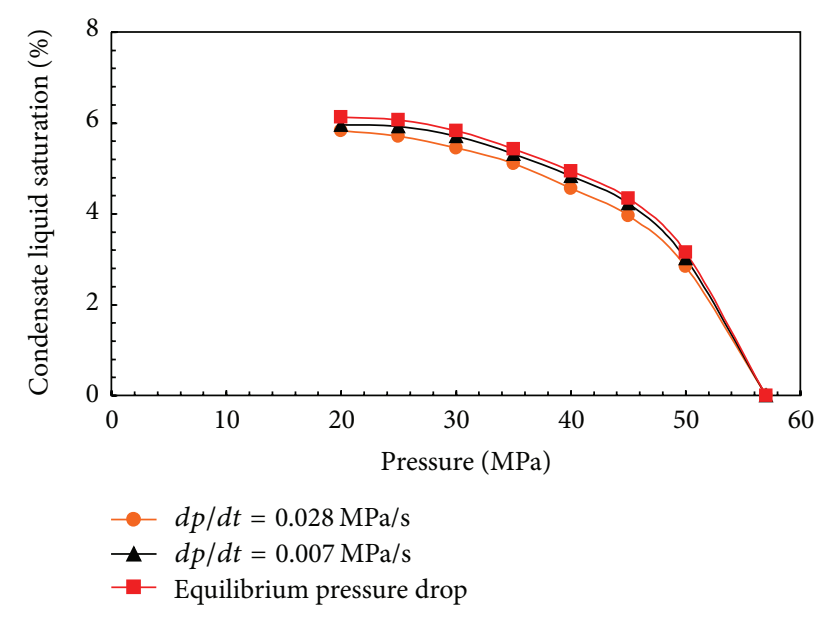

FIgURE 5: The contrast curve about the calculated retrograde condensate oil saturation in the equilibrium pressure drop by the modified PR EOS, the calculated retrograde condensate oil saturation of different pressure drop rate $(d p / d t=0.007 \mathrm{MPa}$, $d p / d t=0.028 \mathrm{MPa}$ ) in the nonequilibrium pressure drop using (15).

more the cumulative condensate oil can be produced in the nonequilibrium pressure drop and the lower the retrograde condensate oil saturation is in the formation. Therefore, it can be concluded that the nonequilibrium effect can reduce the retrograde condensate oil saturation in the near wellbore zone and have a certain positive role in slowing retrograde condensation pollution in the near wellbore zone.

\section{Conclusions}

(1) The condensate oil precipitation lags behind because of the nonequilibrium effect. This part that delayed will be produced to the ground with natural gas. So in the process of production of condensate gas reservoir with gaseous water, the appropriate nonequilibrium effect can increase condensate oil and condensate water recovery.

(2) When the system pressure is higher than the maximum retrograde condensation pressure, condensate oil content is higher and the nonequilibrium effect is stronger. So in the different stages of condensate gas field exploitation, the degree of nonequilibrium effect is different. Therefore by choosing an appropriate exploiting opportunity and properly increasing the nonequilibrium effect an efficient production of a condensate gas reservoir can be achieved.

(3) The average relative error of the retrograde condensate oil saturation calculated by modified PR equation is $4.49 \%$. It is a suggestion that the modified PR equation is more suitable for representing the phase behavior characteristics of condensate oil and gas system with gaseous water under the high temperature and high pressure condition.

(4) In the different stages of condensate gas field with gaseous water exploitation, the nonequilibrium effect has different influences on the condensate oil and condensate water. In other words, nonequilibrium effect has a greater influence on condensate oil in the high pressure stage but has a greater influence on condensate water in the low pressure stage. Therefore, choosing an appropriate exploitation opportunity and properly increasing the nonequilibrium effect are helpful to slow retrograde condensation pollution in the near wellbore area and reverse osmosis water locking damage degree and improve the production efficiency of condensate gas reservoir with gaseous water.

\section{Nomenclature}

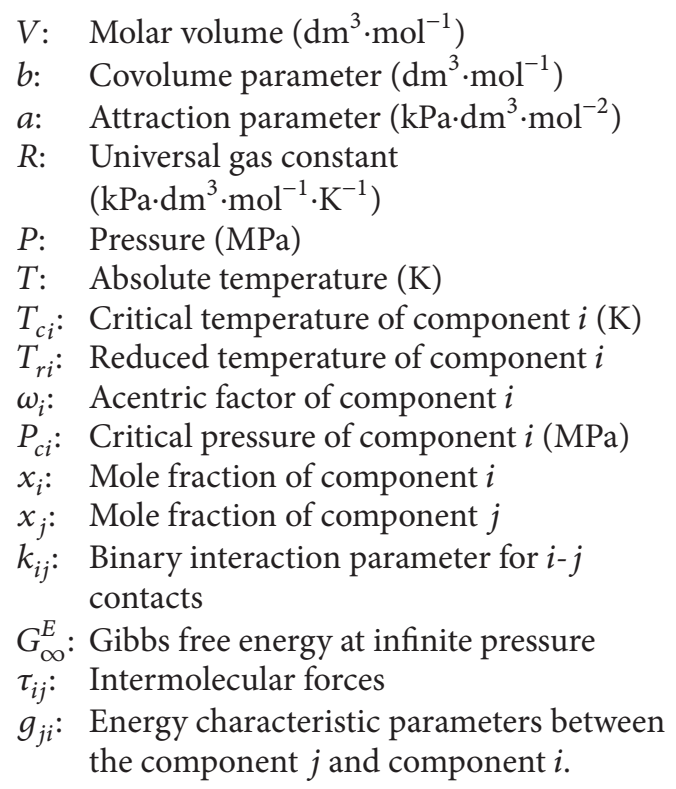

\section{Conflict of Interests}

Here, all the authors solemnly declare that there is no conflict of interests regarding the publication of this paper.

\section{Acknowledgments}

The authors wish to acknowledge anonymous reviewers for constructive comments and suggestions for improving this paper. The authors also wish to thank the anonymous Associate Editor for his handling of the paper and additional suggestions. This work was supported by National Science and Technology Major Project of China (no. 2011ZX05016005-2) and a Grant from the National Natural Science Foundation of China (no. 50604011).

\section{References}

[1] Y. Li, B. Li, Y. Hu et al., "Water production analysis and reservoir simulation of the Jilake condensate gas field," Petroleum Exploration and Development, vol. 37, no. 1, pp. 89-93, 2010.

[2] S. Zendehboudi, M. A. Ahmadi, L. James, and I. Chatzis, "Prediction of condensate-to-gas ratio for retrograde gas condensate reservoirs using artificial neural network with particle swarm optimization," Energy \& Fuels, vol. 26, pp. 3432-3447, 2012.

[3] S. A. Jokhio, D. Tiab, and F. Escobar, "Forecasting liquid condensate and water production in two-phase and three-phase gas condensate systems," in Proceedings of the SPE Annual Technical Conference and Exhibition, San Antonio, Tex, USA, September-October 2002, SPE 77549. 
[4] L. F. Ayala and J. P. Kouassi, "The similarity theory applied to the analysis of multiphase flow in gas-condensate reservoirs," Energy \& Fuels, vol. 21, no. 3, pp. 1592-1600, 2007.

[5] D. V. Nichita, D. Broseta, P. Elhorga, and F. Montel, "Pseudo-component delumping for multiphase equilibrium in hydrocarbon-water mixtures," Petroleum Science and Technology, vol. 26, no. 17, pp. 2058-2077, 2008.

[6] M. B. Oliveira, J. A. P. Coutinho, and A. J. Queimada, "Mutual solubilities of hydrocarbons and water with the CPA EoS," Fluid Phase Equilibria, vol. 258, no. 1, pp. 58-66, 2007.

[7] K. S. Pedersen and J. Milter, "Phase equilibrium between gas condensate and brine at HT/HP conditions," in Proceedings of the SPE Annual Technical Conference and Exhibition, Houston, Tex, USA, September 2004, SPE 90309.

[8] N. Lindeloff and M. L. Michelsen, "Phase envelope calculations for hydrocarbon-water mixtures," in Proceedings of the SPE Annual Technical Conference and Exhibition, San Antonio, Tex, USA, September-October 2002, SPE 77770.

[9] S. KoKal, A. D. Mohammad, and S. Sayegh, "Phase behavior of a gas condensate/water system," in Proceedings of the SPE Annual Technical Conference and Exhibition, Dallas, Tex, USA, October 2000, SPE 62931.

[10] K. L. Wu, X. F. Li, and H. T. Wang, "A quantitative model for evaluating the impact of volatile oil non-equilibrium phase transition on degassing," Petroleum Exploration and Development, vol. 39, pp. 636-643, 2012.

[11] F. Civan, "Including nonequilibrium relaxation in models for rapid multiphase flow in wells," SPE Production and Operations, vol. 21, no. 1, pp. 98-106, 2006.

[12] G. E. Paredes, A. V. Rodríguez, and E. G. Martíneza, “A numerical analysis of non-equilibrium thermodynamic effects in an oil field: two-equation model," Petroleum Science and Technology, vol. 31, pp. 192-203, 2013.

[13] G. G. Michel and F. Civan, "Modeling nonisothermal rapid multiphase flow in wells under nonequilibrium conditions," SPE Production and Operations, vol. 23, no. 2, pp. 125-134, 2008.

[14] X. D. Kang, X. F. Li, and Y. J. Liu, "Influence on well productivity of high-velocity flow in gas condensate reservoirs," in Proceedings of the 2nd International Symposium on Multiphase, Non-Newtonian and Reacting (Flows '04), vol. 2, pp. 362-366, Hangzhou, China, 2004.

[15] F. Civan, "Modeling well performance under nonequilibrium deposition conditions," in Proceedings of the SPE Production and Operations Symposium, Oklahoma City, Okla, USA, March 2001, SPE 67234.

[16] W. J. Wu, P. Wang, and M. Delshad, "Modeling non-equilibrium mass transfer effects for a gas condensate field," in Proceedings of the SPE Asia Pacific Conference, Kuala Lumpur, Malaysia, March 1998, SPE 39746.

[17] F. S. Alavi, D. Mowla, and F. Esmaeilzadeh, "Production performance analysis of Sarkhoon gas condensate reservoir," Journal of Petroleum Science and Engineering, vol. 75, no. 1-2, pp. 44-53, 2010.

[18] E. L. Zhu, Z. Wei, and Z. W. Wang, Natural Gas Extraction Process, Petroleum Industry Press, Beijing, China, 1993.

[19] P. Y. Yang, G. X. Qi, and L. R. Chen, Condensate Gas Field Development, Petroleum Industry Press, Beijing, China, 1983.

[20] D. Y. Peng and D. B. Robinson, "A new two-constant equation of state," Industrial and Engineering Chemistry: Fundamentals, vol. 15, pp. 59-64, 1976.
[21] SY/T5542-2009, "Analysis for reservoir fluids physical properties," China National Oil and Gas Industry Standards, 2009.

[22] A. H. Mohammadi, A. Chapoy, B. Tohidl, and D. Richon, "Gas solubility: a key to estimating the water content of natural gases," Industrial and Engineering Chemistry Research, vol. 45, no. 13, pp. 4825-4829, 2006.

[23] L. John and R. A. Walter, Gas Reservoir Engineering, Petroleum Industry Press, Beijing, 2007, Translated by Wang Y. P., Guo W. K., Pang Y. M. et al. 

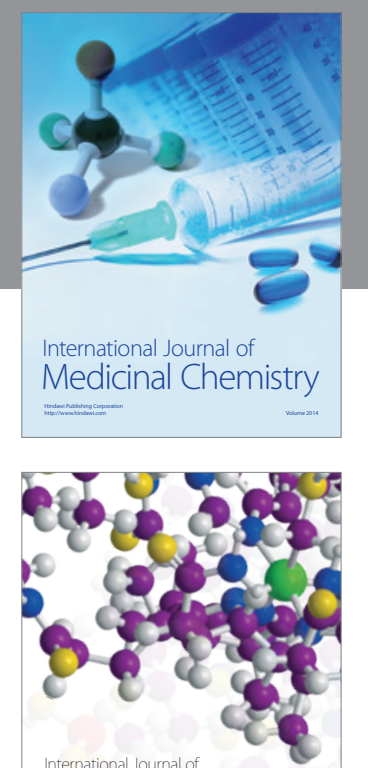

\section{Carbohydrate} Chemistry

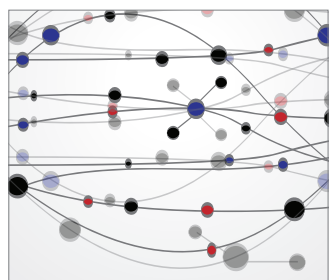

The Scientific World Journal
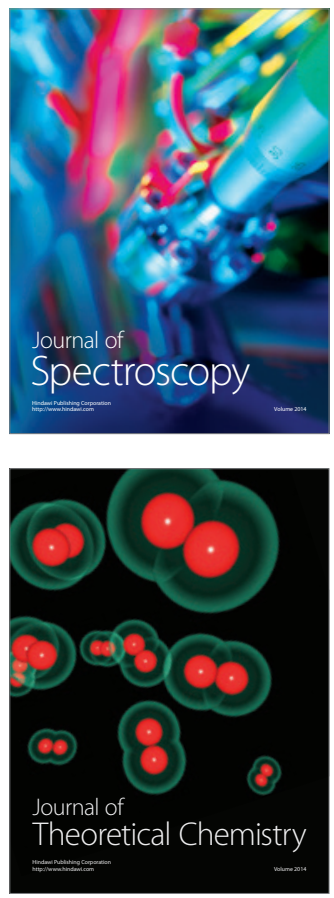
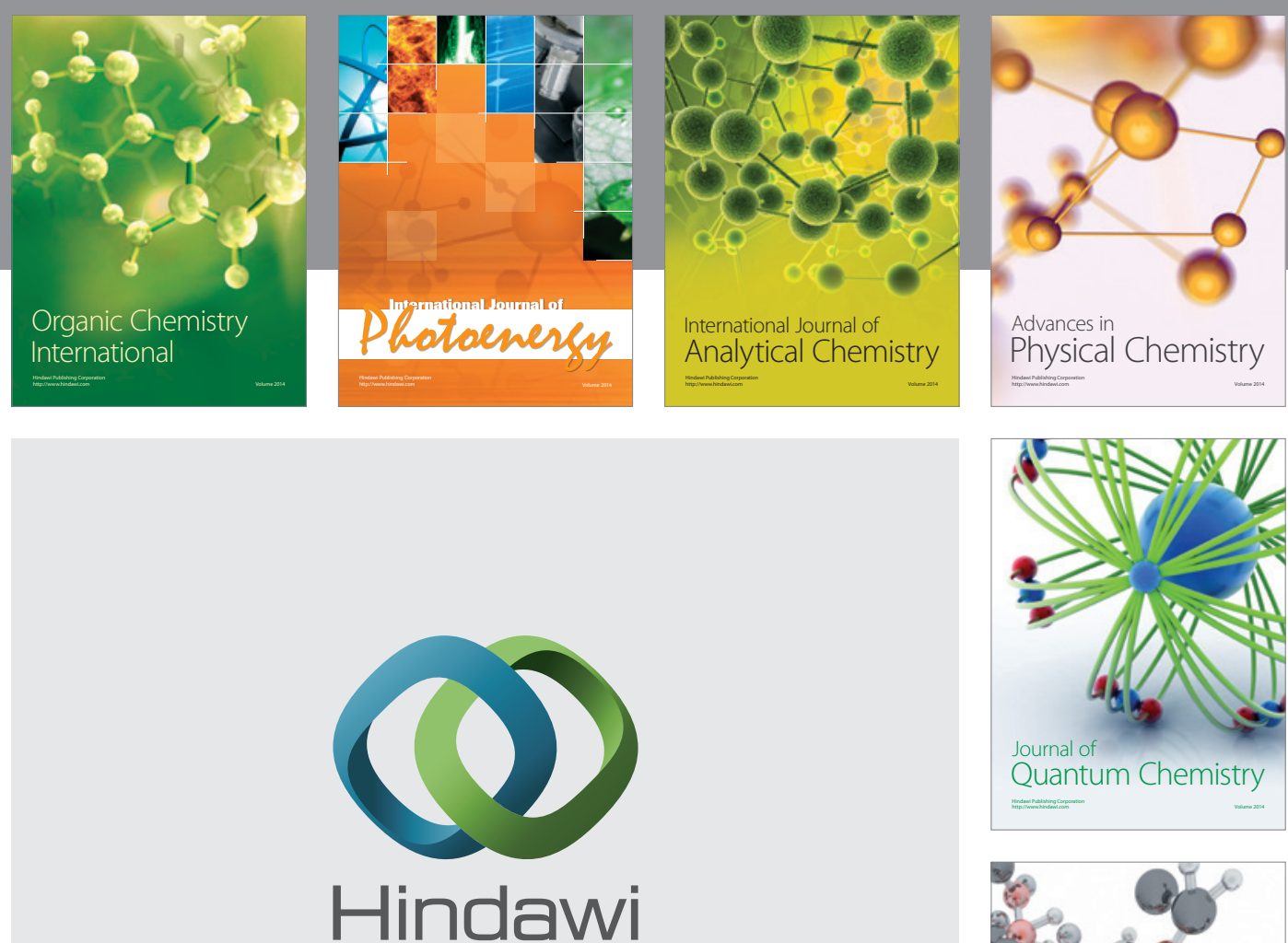

Submit your manuscripts at

http://www.hindawi.com

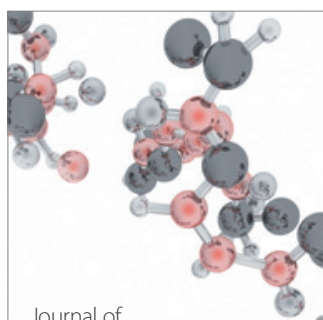

Analytical Methods

in Chemistry

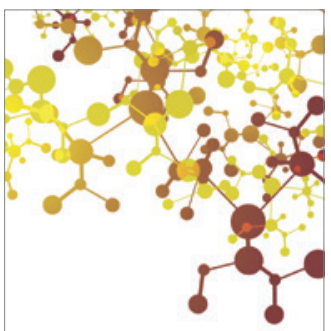

Journal of

Applied Chemistry

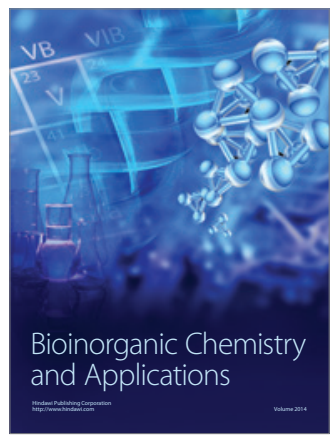

Inorganic Chemistry
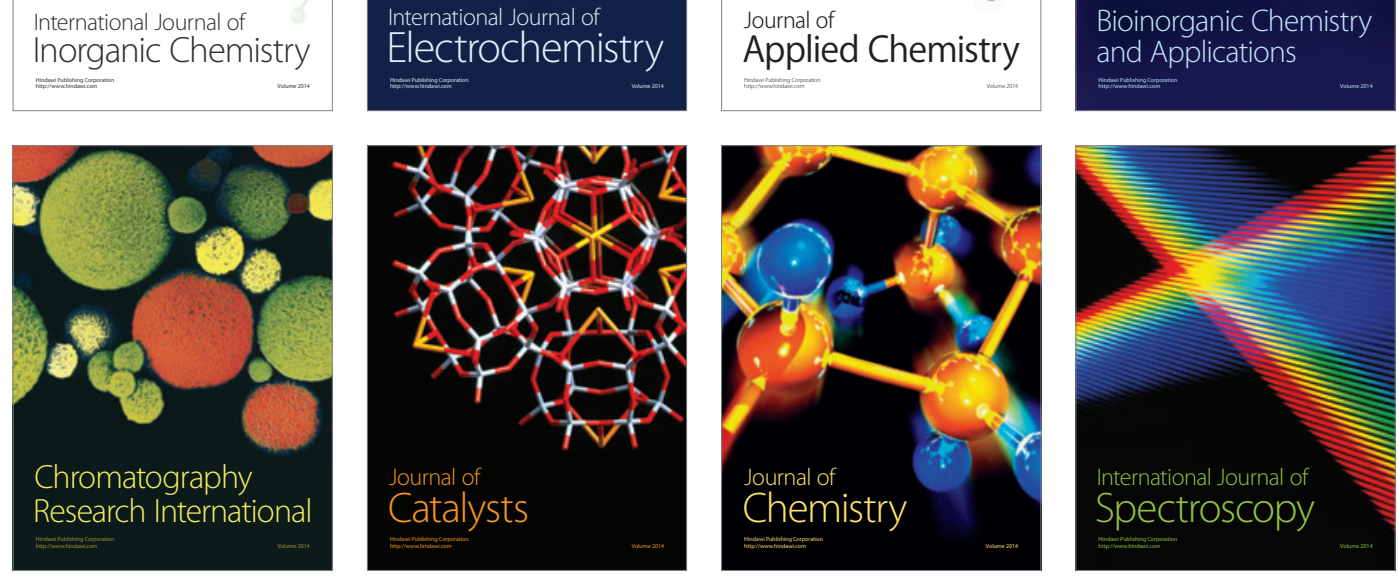